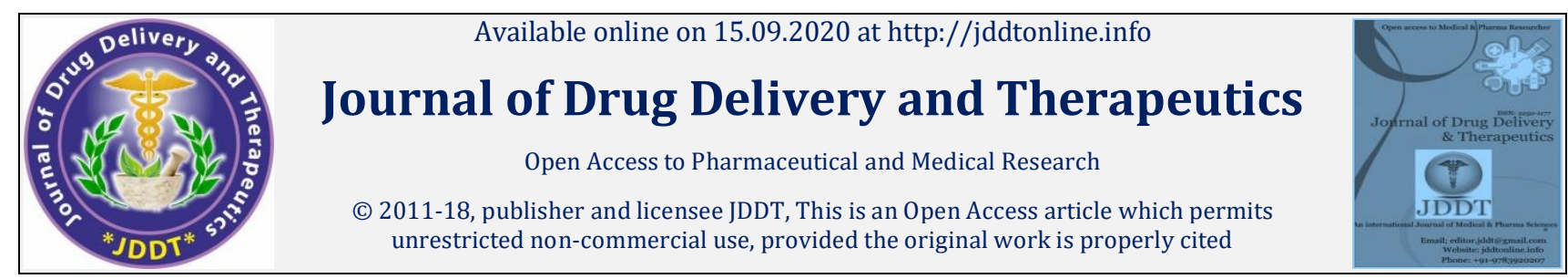

Open $\odot$ Access

Research Article

\title{
Fixed Dose Oral Dispersible Tablet of Bitter Drug Using Okra Mucilage: Formulation and Evaluation
}

\author{
Pintu Dhar a\$, Himangshu Sarmaa,b \$*, Hemanta Kumar Sharma a* \\ a Department of Pharmaceutical Sciences, Dibrugarh University, Dibrugarh, Assam, India-786004 \\ b Life Sciences Division, Institute of Advanced Study in Science \& Technology, Guwahati, Assam, India-781035 \\ \$ These authors have contributed equally
}

\begin{abstract}
Background: The solid oral dosage forms containing bitter drugs need improved palatability for administration. Formulation scientists have given attention to the improvement of taste masking technologies and utilised various strategies.

Objective: The present work aimed to mask the bitter taste of Promethazine Hydrochloride by formulating Oral Dispersible Tablets using Okra mucilage as a taste-masking agent.

Methods: The Okra mucilage was extracted from Okra by the aqueous extraction process. An emulsion solvent diffusion technique was used for masking the bitter taste of Promethazine Hydrochloride by using Okra mucilage. The Oral Dispersible Tablet was prepared by the wet granulation method. The mucilage and the formulation were characterized and evaluated by standard methods and protocols.

Results: Taste masking of the bitter drug was successfully achieved by Okra mucilage. The DSC and FTIR study revealed that the drug molecule was compatible with okra mucilage and drug entrapment efficacy was found to be $94.76 \%$. The palatability test asserted that masking of the bitter taste of the drug. The In vitro drug release study showed that the F7 tablet batch has a better drug release rate and followed non-fickian mechanism of drug release.
\end{abstract}

Conclusion: Thus, taste masking with Okra mucilage was successful and this opens opportunities for application of common edible substance s in formulation development.

Keywords: Fast disintegrating tablet; Natural polymer; Mouth dissolving tablet; Promethazine Hydrochloride; Taste masking

Article Info: Received 16 July 2020; Review Completed 22 Aug 2020; Accepted 30 August 2020; Available online 15 September 2020

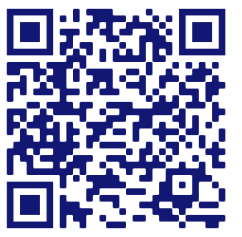

Cite this article as:

Dhar P, Sarma H, Sharma HK, Fixed Dose Oral Dispersible Tablet of Bitter Drug Using Okra Mucilage: Formulation and Evaluation, Journal of Drug Delivery and Therapeutics. 2020; 10(5):149-158

http://dx.doi.org/10.22270/jddt.v10i5.4294

Himangshu Sarma, Life Sciences Division, Institute of Advanced Study in Science \& Technology, Guwahati, Assam, India-781035

Hemanta Kumar Sharma, Department of Pharmaceutical Sciences, Dibrugarh University, Dibrugarh, Assam, India-786004

\section{INTRODUCTION}

The progress of Oral Dispersible Tablets (ODTs) has acquired more considerable attention among researchers, formulation scientist as well as pharmaceutical industries since the last decade. The ODT formulations are formulated to dissolve or disintegrate quickly at the buccal cavity on exposure to saliva without any addition of water in contrast to the conventional tablet dosage forms ${ }^{1}$. The different names of ODTs are known as quick disintegrating tablets, mouth dissolving tablets, fast disintegrating tablets, rapiddissolving tablets and porous tablets etc. The novel ODTs are designed for patients having trouble in swallowing or chewing and also suitable for quick medication for critical patients or traveling patients (motion sickness), who are unable to access water for easy administration ${ }^{2,3}$. The ODTs are put inside the buccal cavity; consequently, tablets are allowed to rapidly disintegrate owing to salivary penetration via the pores of the tablet core without chewing by the patients. Mostly, the disintegration time of ODT is less than one minute (DT $<1$ minute). However, the actual disintegration time varies from 5 to 30 seconds in different patients ${ }^{4}$. Thus, the active agent can rapidly dissolve in the saliva and be absorbed through whatever membrane it encounters, during deglutition, unless it is protected from pre-gastric absorption. The tablets disintegrate in the mouth in less than 30 seconds by the mechanism of high swelling ability, chemical reaction or capillary action. The resulting suspension is swallowed without the need for water, making this dosage form a convenient. So, ODTs are potentially more effective as an alternative to conventional solid dosage forms 5 .

The advantages of ODTs include, it can be given to the patients who cannot swallow (older people, stroke victims, bedridden patients, patients with esophageal problems etc.), 
thus improve patient compliance and increased bioavailability. Moreover, OTDs can provide rapid absorption of drugs through the pre-gastric absorption site. The risk of choking or suffocation during oral administration of conventional formulations due to physical obstruction is avoided, thus provides more safety. The disadvantages include its hygroscopicity in nature. So, it must be stored in a dry place and also required special packaging for proper stabilization \& safety of the product ${ }^{6-8}$.

The Okra mucilage is a natural polymer, which is a nonstarch, a linear water-soluble polysaccharide extracted from the raw unripe Okra fruit (Abelmoschus esculentus (L.) Moench, Family Malvaceae). It has a property like swelling, binding, suspending, taste masking activities on bitter drugs. Okra mucilage could mask the taste of the drug sufficiently long enough in the oral cavity for fast dissolving tablets 9,10.

Taste masking is done for bitter and unpalatable drugs to increase palatability. It is done by various physical and chemical methods that prevent the interaction of taste buds with drugs. Numerous taste-masking approaches are commonly utilized to overcome bad taste of the drug, for instance, by giving a physical barrier in-between the drug and the taste buds across the drug uptake by granulation, encapsulation, coating; by incorporating the sweetener and flavouring agents, that may change the human taste perception; by reduction of drug solubility in saliva, where a balance between reduced solubility and bioavailability must be achieved; or to alter the ability of the drug to interact with taste receptor via chemical modification (Prodrug and salt forms) or by making a complex with an ion exchange resin (e.g. Tulsion335), solid dispersion method, drug particle coating technique etc. that are utilized to successfully mask the bitter taste of the drug in all types of formulations ${ }^{11-13}$.

Considering the above information, it is thought to be worthy of masking the taste of the drug with Okra mucilage and of formulating ODTs for better therapeutic efficacy. In the present study, Promethazine Hydrochloride i.e. (RS) dimethyl (2-phenothiazine-10-yl-propyl) amine hydrochloride (PMZ) is used as a model drug. PMZ is a firstgeneration $\mathrm{H}_{1}$ receptor antagonist. It is used as an antihistaminic as well as an antiemetic agent 14,15. In conventional dosage forms, it undergoes the first-pass metabolism, where the oral bioavailability is reduced to $27 \%$ from $88 \% 16$. In the present study, an attempt was made to formulate Oral disintegrating tablets (ODTs) of PMZ using Okra mucilage as a taste-masking agent to mask the intensely bitter taste of the above drug.

\section{MATERIALS AND METHOD}

Promethazine Hydrochloride (PMZ) was obtained as a gift sample from Quality Pharma Pvt. Ltd., Dibrugarh, Assam and India. The fresh Okra pods were purchased from local market Dibrugarh, Assam and India. Microcrystalline cellulose (MCC), Starch 1500, Polyvinyl-pyrrolidone (PVP K30), Croscarmellose sodium, Lactose, Sodium starch glycollate (SSG) Polyvinyl alcohol (PVA), Aerosil-200, Vanilla flavour were purchased from Yarrow Chem. Products, Mumbai, India. Sodium starch glycolate, sorbitol were purchased from Himedia Ltd., Mumbai, India.

\section{Extraction of Okra mucilage}

The natural Okra mucilage was extracted by aqueous extraction technique in which water was used as the menstruum under the following consideration 17.

In the aqueous extraction process, the following steps were processed on raw materials to obtain mucilage

\section{Extraction of mucilage}

In this step, the raw Okra pods were initially washed with tap water, followed by rinsing with double distilled water to remove all adhering dirt and dried. Then Okra pods were chopped to remove the seeds and homogenized. Then deionized water was added to homogenized Okra pieces in conical flasks at the ratio of $1: 1.5 \% \mathrm{w} / \mathrm{w}{ }^{18}$. The flasks were sealed and kept on a constant heating bath at $60^{\circ} \mathrm{C}$ for around 4-5 hours with agitation. Throughout the extraction processes, the evaporation rate was asserted to be less than $0.05 \%$. After the specified duration of time, the flasks were kept separately for 1 hour at room temperature to complete removal of the mucilage in water 19 .

The marc was separated from the extract by straining through a tea mesh. The crude mucilage (filtrate) was kept aside in the refrigerator for overnight to the sediment of soluble soils. The supernatant part of crude mucilage was decanted into a clean and dry flask and concentrated on a water bath at $50-60^{\circ} \mathrm{C}$. Three volumes of acetone were used to wash the concentrated samples. The collected precipitate was washed with acetone. Finally, the precipitate was dried at $50-60^{\circ} \mathrm{C}$ in a hot air oven for 4 hours and passed through sieve nos. $120 \& 15020$.

\section{Characterization of Okra mucilage}

After the extraction process, mucilage solutions were tested to ascertain the presence of carbohydrates by performing the Molisch's test and Ruthenium red test respectively. Besides, pH, solubility, swelling index, density and viscosity measurements were carried out on dry powder mucilage 21 .

\section{Drug-excipient compatibility studies}

Fourier Transform Infrared spectroscopy and Differential Scanning Calorimetry studied the possible interaction between the drug and the excipients.

\section{Fourier Transform Infrared spectroscopy (FT-IR) analysis}

The FT-IR spectra of PMZ, Okra mucilage, mucilage coated PTZ and physical mixture of mucilage along with PMZ were analyzed in $\mathrm{KBr}$ pellets using the Bruker Alpha FT-IR spectrophotometer, Germany to distinguish the involvement of any interaction between the drug and polymers.

\section{Differential Scanning Calorimetry (DSC) analysis}

The DSC thermogram of PMZ, Okra mucilage, mucilage coated PMZ, and physical mixtures of PMZ and mucilage were analyzed separately by utilizing a Perkin Elmer JADE DSC (USA) instrument. The samples were placed in an aluminum pan and scanned at a speed of $10^{\circ} \mathrm{C} \mathrm{min}{ }^{-1}$ in the temperature range of $20-300^{\circ} \mathrm{C}$ under the inert nitrogen gas atmosphere and thermograms obtained were observed for any interaction among the components present in the formulation 22 .

\section{Methods for masking the bitter taste of PMZ}

\section{Identification of threshold bitterness concentration PMZ}

A group of ten healthy human volunteers (age 20-25 years) were selected. A series of solutions of PMZ in phosphate buffer of pH 6.8 with concentrations 10, 20, 30, 40, 50, 60, $70,80,90,100 \mu \mathrm{g} / \mathrm{ml}$ were prepared. The volunteers were asked to hold $10 \mathrm{ml}$ of each solution in the oral cavity for 30 seconds. The taste of PMZ was recorded on a numerical scale from 0 to 4, where $0,1,2,3$ and 4 were represented with no bitterness, threshold bitter, bitter, moderate bitterness and strong bitterness respectively. Based on the opinion of the volunteers, the threshold bitterness concentration of PMZ was determined 13,23. 


\section{Taste masking by emulsion solvent diffusion Technique}

In this technique, PMZ and powdered Okra mucilage were taken in a ratio of $(1: 1,1: 2,1: 3,1: 4,1: 5$ and 1:6) to obtain an emulsion. The homogenous mixture of PMZ and Okra mucilage powder was first dissolved in a mixture of methanol, acetone and dichloromethane (1:2:3). The above solution was slowly poured in a $1 \%$ aqueous Polyvinyl Alcohol (PVA) solution maintained at $40-50{ }^{\circ} \mathrm{C}$ with continuous stirring at $2000 \mathrm{rpm}$ for $2-3$ hours to form an emulsion. The emulsion was kept in a deep freezer at $-35^{\circ} \mathrm{C}$ to solidify. Finally, solidification of the formulation was carried out by Lyophilization technique 24 .

\section{Characterization of taste-masked PMZ}

\section{Evaluation of In vitro taste-masking:}

A required amount of taste masking substance (equivalent to $25 \mathrm{mg}$ of PMZ) was dissolved in six volumetric flasks containing $10 \mathrm{ml}$ of phosphate buffer of $\mathrm{pH}$ 6.8. The solutions were shaken for $0,15,30,60,120$ and 300 seconds and filtered. The amount of PMZ content in each filtrate was determined at the respective time. The PMZ content at the end of 120 seconds was considered as the significance of taste masking. It should be less as compared to the threshold bitterness concentration of the PMZ ${ }^{13}$.

\section{Drug loading}

The drug content in the taste-masked product was determined in triplicate by UV Spectrophotometric method by following formula (1) 25 .

Percentage of drug loading $=$

$$
\frac{\text { Amount of drug in substance recovered }}{\text { Total weight of substance }} \times 100 \ldots . . \text { Eq. }
$$

\section{Drug encapsulation efficiency}

The percentage of drug encapsulation efficacy of coated PMZ was determined by using of following formula (2) 25 .

Percentage of drug encapsulation efficiency =

$$
\frac{\text { Amount of drug in substance recovered }}{\text { The total amount of drug added }} \times 100 \ldots . \text { Eq. }
$$

\section{Preparation of Oral Dispersible Tablets of PMZ Using Okra Mucilage}

Total 10 batches of ODT of PMZ were formulated by the wet granulation method. The preparation of the tablets was carried out according to three different steps. The steps were given as follows-

\section{Preparation of fast melt granule}

All the granulating materials (Table 1) were accurately weighed and sifted through a sieve separately. Then SSG, sorbitol, Starch 1500, Lactose were mixed (Dry mix) and PVPK- 30 was dissolved in a binder solution. The binder solution was slowly poured in the dry mixed powder to obtain wet mass. The granules were prepared by passing the wet mass through a sieve no $12 \#$ and dried at a temperature of $40-50^{\circ} \mathrm{C}$.

\section{Preparation of final blend and tablet compression}

The disintegrate, glidants, lubricant materials were sifted through a different type of sieves separately, such as coated substances and fast melt granule through 40\#, sorbitol, vanilla flavour, SDS, talc, aerosol- 200 through 60\#, MCC, CCS and SSG through 30\#. All the sifted material except aerosil200 were mixed in a polyethylene bag for 15 minutes. Finally, aerosol-200 was added to it and mixed for 3 minutes. The compression of tablets was carried out using Shakti 10 station compression machine.

\section{Powder fineness}

Five different mesh sizes of sieves were taken, for instance, $20 \#, 40 \#, 60 \#, 80 \#$ and 100\#. All the sieves were arranged in descending order, i.e., sieve of larger particle size (20\#) was at the top and the smallest one at the bottom (100\#). The bottom sieve was attached to the receiving pan. Accurately weighed quantity of the sample was placed on the top and agitated for 5 minutes. Then each sieve was carefully removed and the weight of material on each sieve was determined. The fineness of the powder may be expressed as a percentage $(\% \mathrm{w} / \mathrm{w})$ passing through the sieve(s). Percentage of fineness below 60\# mesh size was calculated by using the following formula:

Percentage of fineness below 60\# =

$$
\frac{\text { Weight of fines Collected below } 60 \#(\mathrm{gm})}{\text { Initial Weight of Lubricated granules }(\mathrm{gm})} \times 100 \ldots . . \text { Eq. }
$$

\begin{tabular}{|c|c|c|c|c|c|c|c|c|c|c|c|}
\hline \multirow{2}{*}{$\begin{array}{l}\text { Sl. } \\
\text { No } \\
\text {. }\end{array}$} & \multirow[t]{2}{*}{ Name of ingredients } & \multicolumn{10}{|c|}{$\begin{array}{l}\text { Formulation } \\
\text { Quantity ingredients (in mg) per Tablet }\end{array}$} \\
\hline & & F1 & F2 & F3 & F4 & F5 & F6 & F7 & F8 & F9 & F10 \\
\hline 1 & Coated Substances & 175 & 175 & 175 & 175 & 175 & 175 & 175 & 175 & 175 & 175 \\
\hline 2 & Fast Melt Granule & 150 & 150 & 150 & 150 & 150 & 150 & 150 & 150 & 150 & 150 \\
\hline 3 & Sorbitol & 2 & 2 & 2 & 2 & 2 & 2 & 2 & 2 & 2 & 2 \\
\hline 4 & MCC & 33 & 31 & 29 & 27 & 33 & 31 & 29 & 27 & 30 & 26 \\
\hline 5 & $\mathrm{CCS}$ & 3 & 5 & 7 & 9 & - & - & - & - & 3 & 5 \\
\hline 6 & SSG & - & - & - & - & 3 & 5 & 7 & 9 & 3 & 5 \\
\hline 7 & Vanilla flavour & 2 & 2 & 2 & 2 & 2 & 2 & 2 & 2 & 2 & 2 \\
\hline 8 & SDS & 2 & 2 & 2 & 2 & 2 & 2 & 2 & 2 & 2 & 2 \\
\hline 9 & Talc & 3 & 3 & 3 & 3 & 3 & 3 & 3 & 3 & 3 & 3 \\
\hline 10 & Aerosil- 200 & 5 & 5 & 5 & 5 & 5 & 5 & 5 & 5 & 5 & 5 \\
\hline \multicolumn{2}{|c|}{ Total } & 375 & 375 & 375 & 375 & 375 & 375 & 375 & 375 & 375 & 375 \\
\hline
\end{tabular}

Table 1: Compositions used in tablet formulation 


\section{Evaluation of blends}

The final mixed blend was evaluated by determination of various parameters such as Bulk Density (BD), Tapped Density (TD), Compressibility Index (CI), Hausner's Ratio (HR), Particle size distribution (PSD), Loss on drying (LOD), angle of repose, percentage (\%) of yield for the final mixed blend was calculated by using the following formula (4) 26.

Percentage yield $=\frac{\text { The actual Weight of Blend }}{\text { Theoretical Weight of Blends }} \times 100 \ldots$ Eq. (4)

\section{Evaluation of formulated tablets}

Tablets were evaluated for weight variation, tablet thickness and diameter, hardness, friability, disintegration time, waiting time, the water absorption ratio as per standard methods 26 .

\section{In vitro drug disintegration}

One tablet from each batch was introduced into six cylindrical tubes of the disintegration test apparatus. The tubes were moved upward and downward at a rate of 29 to 32 strokes per minute in $900 \mathrm{ml}$ distilled water at $37 \pm 2^{\circ} \mathrm{C}$. The time taken to pass all the fragments of the tablet through the mesh of the cylindrical tubes was considered as disintegration time.

\section{In vitro drug release study}

In vitro drug release test was performed in phosphate buffer solution (PBS) of pH 6.8: The paddle method (USP Apparatus II) was used to carry out the dissolution test of the formulation of all batches $(n=10)$ in $900 \mathrm{ml}$ of PBS. The study medium was kept in a thermostatically controlled water bath, maintained at $37 \pm 0.5^{\circ} \mathrm{C}$. The pre-weighed tablet was then introduced into the dissolution jar and the paddle was rotated at the rate of $50 \mathrm{rpm}$. The $5 \mathrm{ml}$ of sample solution was withdrawn from the dissolution compartment at regular intervals $(0,15,30,45,60,75,90,105,120,135,150,165$, $180,195,215,240,255,285$ and 300 minutes) and immediately replaced with $5 \mathrm{ml}$ of dissolution media to maintain a constant volume. The samples were filtered through Whatman filter paper and the absorbance was determined by UV- Visible Spectrophotometer at $249.6 \mathrm{~nm}$ (Shimadzu UV-1800) 25,27,28. The cumulative percentages of drug released were calculated.

\section{Wetting time}

A tissue paper folded twice was positioned in a small petri dish (internal diameter of $5 \mathrm{~cm}$ ) having $6 \mathrm{ml}$ of distilled water. A tablet was placed on the folded tissue paper. Finally, the time needed for completion of the wetting of the tablet was measured.

\section{Water absorption ratio}

A tissue paper folded twice was positioned in a small petri dish (internal diameter $=6.5 \mathrm{~cm}$ ) having $5 \mathrm{ml}$ of distilled water. A tablet was placed on the folded tissue paper. The wetted tablet was weighed. The test was done in triplicate. The water absorption ratio (R) was determined according to the following equation

$$
\begin{aligned}
& \text { Water absorption ratio }(R)=\frac{W a-W b}{W a} \times 100 \ldots . \text { Eq. (5) } \\
& W_{a}=\text { weight of the tablet before the test } \\
& W_{b}=\text { weight of the tablet after water absorption. }
\end{aligned}
$$

\section{Characterization of formulated tablets}

The physical characterization of the final formulation was carried out similarly as performed in the case of pure drug and mucilage by using FT-IR, DSC.

\section{Drug release kinetics of ODTs}

The kinetics of drug release from ODTs were determined by different In vitro kinetics models such as zero-order (Eq. 6), first-order (Eq. 7), Higuchi (Eq. 8) and Korsmeyer-peppas model (Eq. 9).

$$
\begin{array}{ll}
F=K_{0} t & \text { Eq. (6) } \\
\ln (1-F)=-K_{1} t & \text { Eq. (7) } \\
F=K_{H} t^{1 / 2} & \text { Eq. (8) } \\
M_{t} / M_{\infty}=K_{K} t^{n} & \text { Eq. (9) }
\end{array}
$$

Where the $\mathrm{F}$ is a fraction of drug release in time $t$ and $K_{0}, K_{1}$, $\mathrm{K}_{\mathrm{H}}$ and $\mathrm{K}_{\mathrm{K}}$ are rate constants for zero order, first order, Higuchi model and Korsmeyer-Peppas model respectively. $M_{t}$ is the amount of drug release at time $t, M_{\infty}$ is the amount of drug release at infinity and $n$ is diffusion constant 29 . By using the above kinetic model equation, correlation coefficient $\left(\mathrm{R}^{2}\right)$ values and $\mathrm{n}$ were determined. Based on $\mathrm{R}^{2}$ and $n$ value the suitable drug release model as well as the release mechanism of the formulation was identified.

\section{RESULTS}

\section{Physicochemical properties of mucilage:}

From Okra pods $0.48 \% \mathrm{w} / \mathrm{w}$ of mucilage was collected, as shown in table 2. The presence of mucilage in Okra was confirmed by the development of Purple to the violet colour ring and pink colour (Positive) upon the treatment of Molisch's reagents and Ruthenium red test respectively (Table 3). The $\lambda_{\max }$ of the Okra mucilage was observed at $201.00 \mathrm{~nm}$ in UV-VIS Spectrum analysis ${ }^{17}$.

Table 2: Percentage yield of Okra mucilage

\begin{tabular}{|l|l|l|l|l|}
\hline Sl. No. & Batches & $\begin{array}{l}\text { Quantity of Okra pods } \\
\text { (gm) }\end{array}$ & $\begin{array}{l}\text { Weight of mucilage after } \\
\text { drying (gm) }\end{array}$ & $\begin{array}{l}\text { Percentage Yield } \\
(\%)\end{array}$ \\
\hline 1. & Batch 1 & 5000 & 26 & 0.52 \\
\hline 2. & Batch 2 & 5000 & 23 & 0.46 \\
\hline 3. & Batch 3 & 5000 & 28 & 0.56 \\
\hline 4. & Batch 4 & 5000 & 22 & 0.44 \\
\hline 5. & Batch 5 & 5000 & 21 & 0.42 \\
\hline
\end{tabular}


Table 3: Results of the identification test for mucilaginous substances

\begin{tabular}{|l|l|l|l|}
\hline Sl. No. & Description & Observation & Results \\
\hline 1 & Molisch's test & Purple to violet color ring appears & Presence of carbohydrate. \\
\hline 2 & Ruthenium test & Pink color & Present of mucilage \\
\hline
\end{tabular}

\section{Threshold bitterness concentration of PMZ}

The threshold bitterness concentration of PMZ was reported $100 \mu \mathrm{g} / \mathrm{ml}$ by the majority of volunteers (Table 4).

\section{Evaluation of In vitro taste-masking}

It was found that the amount PMZ present in a buffer solution ( $\mathrm{pH}$ 6.8) was less than from the threshold concentration at the end of 120 seconds (showed in table 5).

Table 4: For threshold bitterness concentration of PMZ

\begin{tabular}{|c|c|c|c|c|c|c|c|c|c|c|c|}
\hline \multirow{2}{*}{$\begin{array}{l}\text { Sl. } \\
\text { No }\end{array}$} & \multirow{2}{*}{$\begin{array}{l}\text { Volunte } \\
\text { er Code }\end{array}$} & \multicolumn{10}{|c|}{ Rate of Mouth Feel in different concentration PMZ ( $\mu \mathrm{g} / \mathrm{ml})$} \\
\hline & & 10 & 20 & 30 & 40 & 50 & 60 & 70 & 80 & 90 & 100 \\
\hline 1 & A & 0 & 0 & 0 & 0 & 0 & 0 & 0 & 0 & 0 & 1 \\
\hline 2 & B & 0 & 0 & 0 & 0 & 0 & 0 & 0 & 0 & 1 & 1 \\
\hline 3 & $\mathrm{C}$ & 0 & 0 & 0 & 0 & 0 & 0 & 0 & 0 & 0 & 0 \\
\hline 4 & $\mathrm{D}$ & 0 & 0 & 0 & 0 & 0 & 0 & 0 & 0 & 0 & 1 \\
\hline 5 & $E$ & 0 & 0 & 0 & 0 & 0 & 0 & 0 & 0 & 0 & 1 \\
\hline 6 & $F$ & 0 & 0 & 0 & 0 & 0 & 0 & 0 & 0 & 1 & 1 \\
\hline 7 & G & 0 & 0 & 0 & 0 & 0 & 0 & 0 & 0 & 1 & 1 \\
\hline 8 & $\mathrm{H}$ & 0 & 0 & 0 & 0 & 0 & 0 & 0 & 0 & 0 & 1 \\
\hline 9 & $\mathrm{I}$ & 0 & 0. & 0 & 0 & 0 & 0 & 0 & 0 & 0 & 0 \\
\hline 10 & $\mathrm{~J}$ & 0 & 0 & 0 & 0 & 0 & 0 & 0 & 0 & 0 & 1 \\
\hline
\end{tabular}

Table 5: Amount of PMZ in a different time interval

\begin{tabular}{|c|c|c|}
\hline Volumetric Flask No. & Shaking Time in Second & Concentration in $\mu \mathrm{g} / \mathrm{ml}$ \\
\hline 1 & 0 & 0.16 \\
\hline 2 & 15 & 1.39 \\
\hline 3 & 30 & 1.77 \\
\hline 4 & 60 & 2.05 \\
\hline 5 & 120 & 2.19 \\
\hline 6 & 300 & 05 \\
\hline
\end{tabular}


The drug loading percentage in coated substance was found to be $13.71 \%$, according to equation (2). It might be due to the loss of some excipients during the process.

The drug encapsulation efficiency of mucilage coated substance was found to be $94.76 \%$. Moreover, the $\lambda_{\max }$ of the UV spectrum of the mucilage coated PMZ solution in water was found to be at $249.4 \mathrm{~nm}$, which was similar to the $\lambda_{\max }$ of pure PMZ at PBS pH 6.8. Thus, the drug molecule might be entrapped by the mucilage of the coated formulation.

\section{Interpretation of FT-IR spectrum}

All the typical bands of Okra mucilage were present in the spectrum as in our previous study report (shown in figure 1), where $-\mathrm{NH}_{2}$ group (at $3266.51 \mathrm{~cm}^{-1}$ ), C-H aromatic bond (2937.37 $\left.\mathrm{cm}^{-1}\right),-\mathrm{C}=0$ aldehyde bond (at $1722.63 \mathrm{~cm}^{-1}$ ), $-\mathrm{C}=\mathrm{N}$ group (at $1595.78 \mathrm{~cm}^{-1}$ ), $-\mathrm{CH}_{2}$ group (at $1414.51 \mathrm{~cm}^{-1}$ ) and $\mathrm{CH}_{3}$ group (at $1370.86 \mathrm{~cm}^{-1}$ ) peaks were observed 17.

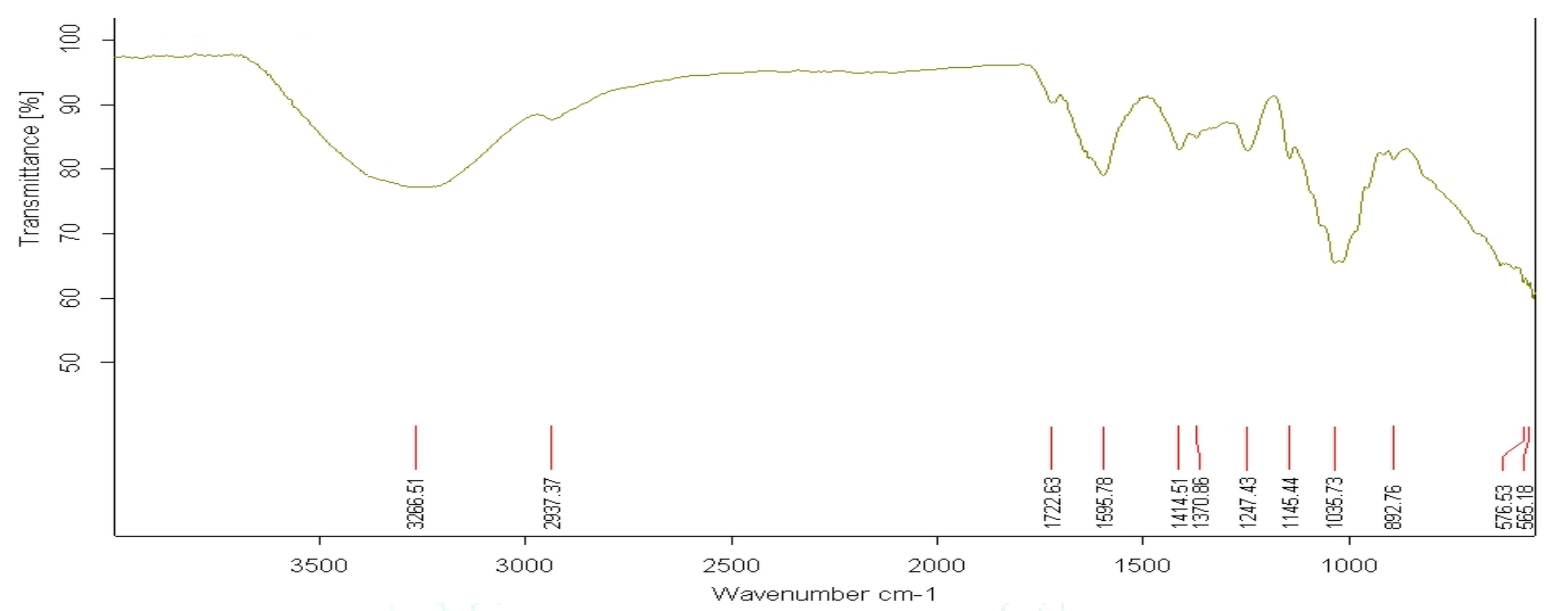

Figure 1: FT-IR spectrum of Okra mucilage

The FT-IR spectra of PMZ, excipients mixture, pure Okra mucilage and coated substances were shown in figure $2(a, b$, c \& d). The pure PMZ spectrum showed sharp characteristic peaks of $\mathrm{C}-\mathrm{H}$ stretching, aromatic $\mathrm{C}=\mathrm{C}$ stretches, $\mathrm{CH}_{3}$ and $\mathrm{CH}_{2}$ bending, C-N is stretching of the tertiary amine band at $2878.33 \mathrm{~cm}^{-1}, 1589.92 \mathrm{~cm}^{-1}, 1453.23 \mathrm{~cm}^{-1}$ and $1332.16 \mathrm{~cm}^{-1}$ respectively.

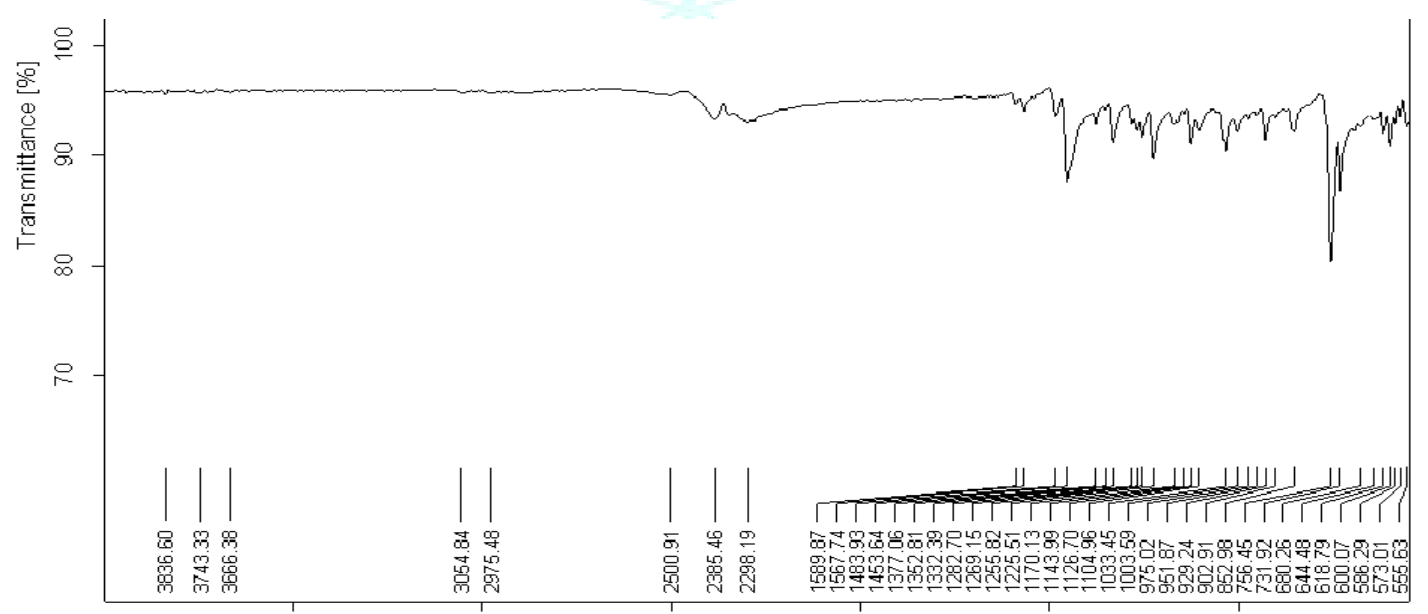

Figure 2 (a): FT-IR Spectrum of PMZ 


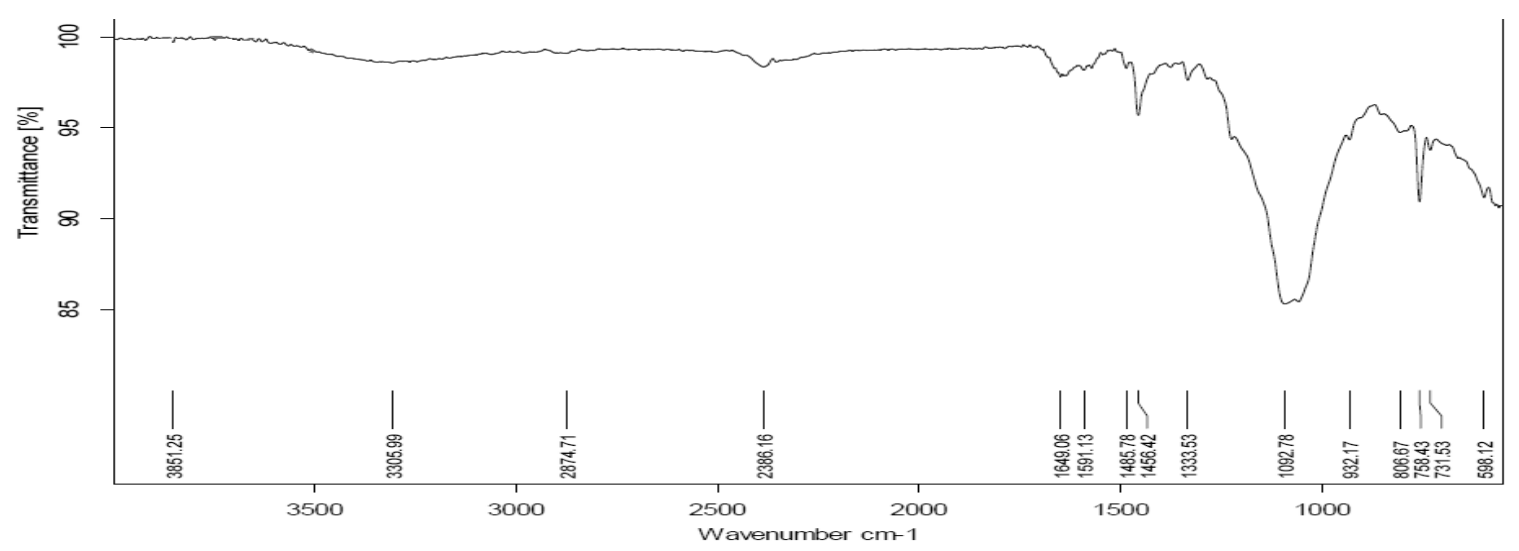

Figure 2 (b): Physical Mixture (Drug with all excipients)

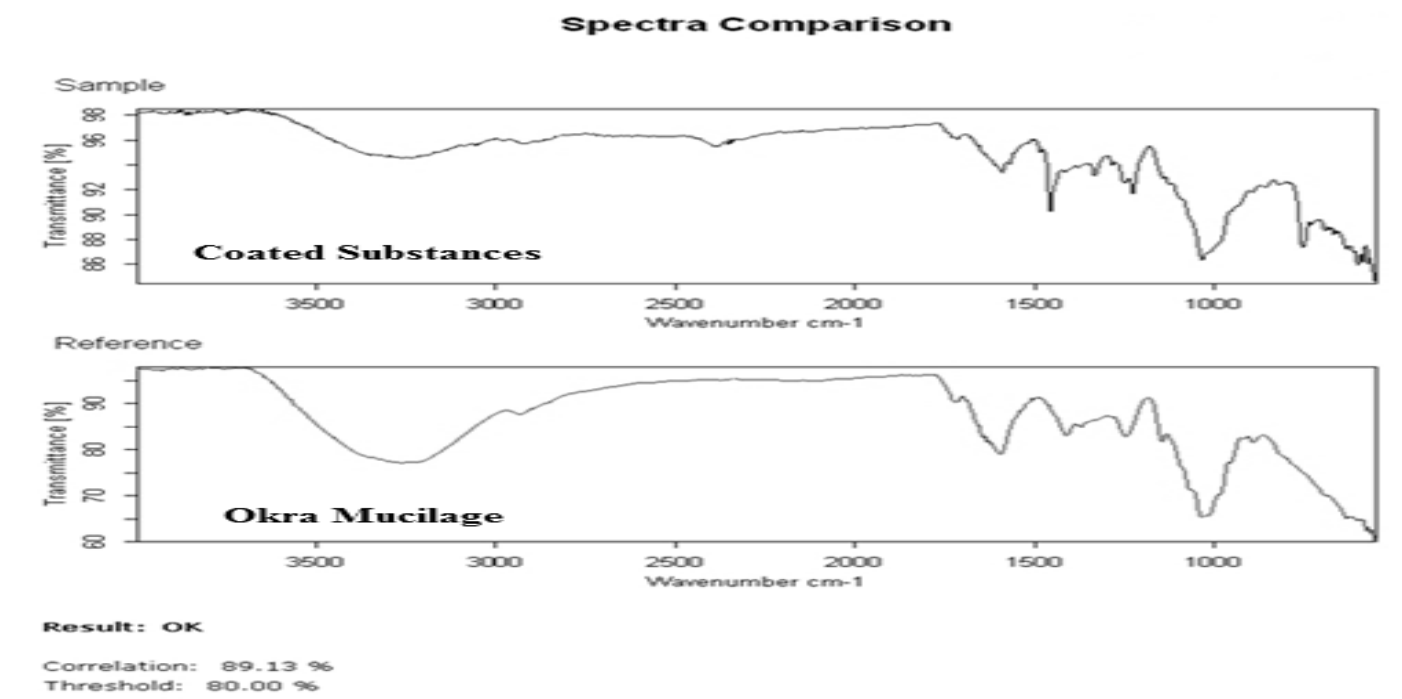

Figure 2 (c): Comparative FT-IR spectra of coated substances with pure okra mucilage

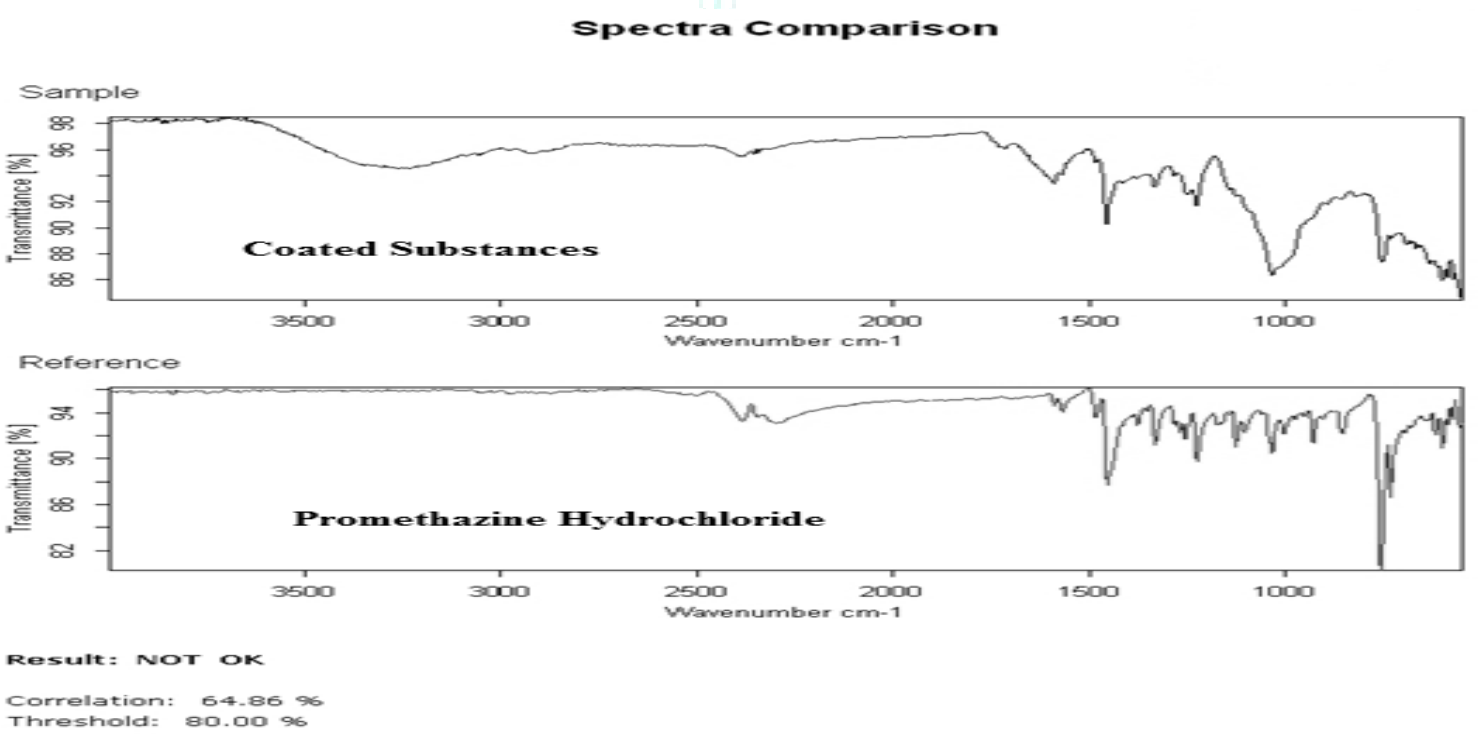

Figure 2 (d): Comparative FT-IR spectra of coated substances with pure drug

\section{Interpretation of DSC thermograms}

The DSC thermogram of Okra mucilage demonstrated a sharp endothermic peak at $105.79^{\circ} \mathrm{C}$. The DSC thermogram of coated substances showed a sharp endothermic peak at $108.21^{\circ} \mathrm{C}$, which is almost similar to the Okra mucilage. The DSC thermograms of pure drug and drug-excipients mixture were shown in figure 3. The DSC thermogram of PMZ showed (curve S1) a sharp endothermic peak at $236.5^{\circ} \mathrm{C}$. The physical blend of PMZ and excipients showed (curve S13) a peak of PMZ at $240.1^{\circ} \mathrm{C}$. 


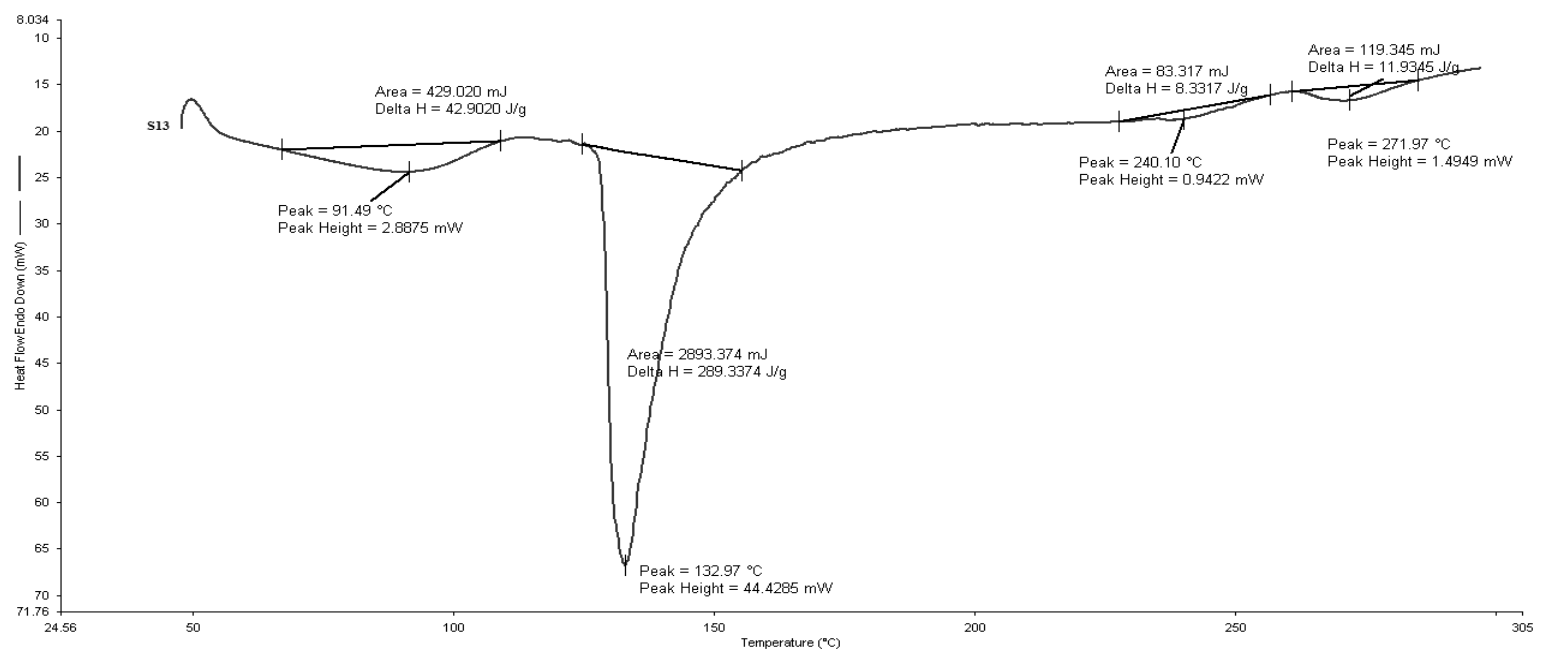

Figure 3: DSC of Physical mixture of PMZ and all excipients

\section{Characterization of blends and tablets}

The compatibility study report of drug-excipients indicated that PMZ and Okra mucilage were compatible with each other. The Cars' index (CI), Hausenr's Ratio (HR) and Angle of repose of powdered blend were observed in between $12.11 \%$ (F3) to $13.66 \%$ (F6), 1.14 to 1.15 and 31.86 (F7) to 33.21 (F1) respectively (Table 6). The ODTs were prepared by compression of the powder blend. It was observed that all the ODTs were a white colour, round in shape, flat on both sides with brake line on one side and passed the weight variation test (Table 7). The hardness of all the ODTs was found to be 3.5 to $5.5 \mathrm{~kg} \mathrm{~cm}^{-2}$ (Table 7). In the dissolution study, the cumulative percentage of drug release of formulating ODTs (F5, F7, F8) was found to be $50 \%$ within 90 minutes (Figure 4).

Table 6: Bulk Density (BD), Tapped Density (TD), Compressibility Index (CI), Hausenr's Ratio (HR), Particle size distribution (PSD), Loss on drying (LOD) and Angle of repose of a powdered blend of batches

\begin{tabular}{|l|l|l|l|l|l|l|l|l|l|l|}
\hline $\begin{array}{l}\text { Sl. } \\
\text { No. }\end{array}$ & Test & F1 & F2 & F3 & F4 & F6 & F7 & F8 & F9 & F10 \\
\hline 1. & \% Yield & 97.28 & 98.33 & 98.26 & 96.85 & 97.11 & 97.86 & 96.32 & 98.21 & 97.11 \\
\hline 2. & LOD & 1.56 & 1.62 & 1.36 & 1.51 & 1.44 & 1.46 & 1.49 & 1.54 & 1.52 \\
\hline 3. & BD $(\mathrm{gm} / \mathrm{ml})$ & 0.416 & 0.423 & 0.421 & 0.433 & 0.436 & 0.422 & 0.435 & 0.419 & 0.422 \\
\hline 4. & TD $(\mathrm{gm} / \mathrm{ml})$ & 0.478 & 0.485 & 0.479 & 0.496 & 0.505 & 0.482 & 0.501 & 0.483 & 0.486 \\
\hline 5. & CI & 12.97 & 12.78 & 12.11 & 12.70 & 13.66 & 12.45 & 13.17 & 13.25 & 13.17 \\
\hline 6. & HR & 1.14 & 1.15 & 1.14 & 1.15 & 1.16 & 1.14 & 1.15 & 1.15 & 1.15 \\
\hline 7. & $\begin{array}{l}\text { Angle of } \\
\text { Repose }(\theta)\end{array}$ & 33.21 & 32.86 & 32.36 & 32.12 & 32.65 & 31.86 & 33.25 & 33.11 & 32.44 \\
\hline 8. & PSD & 46 & 48 & 51 & 43 & 44 & 48 & 48 & 52 & 54 \\
\hline
\end{tabular}

Table 7: Weight Variation, Thickness, Diameter, Hardness and Friability of formulation batches

\begin{tabular}{|l|l|l|l|l|l|l|}
\hline Sl. No. & $\begin{array}{l}\text { Form. } \\
\text { Code }\end{array}$ & $\begin{array}{l}\text { Weight Variation } \\
\text { Avg.(mg) } \pm \text { SD }\end{array}$ & $\begin{array}{l}\text { Thickness } \\
\text { Avg.(mm) } \pm \\
\text { SD }\end{array}$ & $\begin{array}{l}\text { Diameter } \\
\text { Avg.(mm) } \pm \text { SD }\end{array}$ & $\begin{array}{l}\text { Hardness } \\
\left.\text { Avg.(kg/ cm }{ }^{2}\right) \\
\pm \text { SD }\end{array}$ & $\begin{array}{l}\text { Friability }(\%) \pm \\
\text { SD }\end{array}$ \\
\hline 1. & F1 & $376.01 \pm 1.61$ & $4.1 \pm 0.25$ & $10.0 \pm 0.01$ & $4.5 \pm 0.62$ & $0.61 \pm 0.12$ \\
\hline 2. & F2 & $375.03 \pm 1.25$ & $4.0 \pm 0.018$ & $10.0 \pm 0.01$ & $4.0 \pm 0.53$ & $0.54 \pm 0.31$ \\
\hline 3. & F3 & $377.02 \pm 1.65$ & $4.1 \pm 0.13$ & $10.0 \pm 0.00$ & $3.9 \pm 0.51$ & $0.84 \pm 0.11$ \\
\hline 4. & F4 & $376.05 \pm 1.33$ & $4.1 \pm 0.08$ & $10.0 \pm 0.02$ & $4.9 \pm 0.63$ & $0.69 \pm 0.08$ \\
\hline 5. & F5 & $376.07 \pm 1.57$ & $4.3 \pm 0.14$ & $10.0 \pm 0.00$ & $5.2 \pm 0.21$ & $0.55 \pm 0.09$ \\
\hline 6. & F6 & $377.06 \pm 1.69$ & $4.2 \pm 0.18$ & $10.0 \pm 0.01$ & $5.5 \pm 0.36$ & $0.66 \pm 0.12$ \\
\hline 7. & F7 & $375.02 \pm 0.63$ & $4.0 \pm 0.02$ & $10.0 \pm 0.00$ & $4.7 \pm 0.11$ & $0.34 \pm 0.02$ \\
\hline 8. & F8 & $376.04 \pm 1.15$ & $4.3 \pm 0.11$ & $10.0 \pm 0.02$ & $4.5 \pm 0.52$ & $0.49 \pm 0.10$ \\
\hline 9. & F9 & $376.05 \pm 0.95$ & $4.3 \pm 0.19$ & $10.0 \pm 0.02$ & $3.8 \pm 0.41$ & $0.51 \pm 0.14$ \\
\hline 10. & F10 & $375.01 \pm 1.11$ & $4.1 \pm 0.09$ & $10.0 \pm 0.02$ & $3.5 \pm 0.14$ & $0.45 \pm 0.21$ \\
\hline
\end{tabular}


Table 8: Disintegration Time, Wetting Time, Water Absorption ratio, Assay, Fineness of formulation batches

\begin{tabular}{|l|l|l|l|l|l|l|}
\hline $\begin{array}{l}\text { Sl. } \\
\text { No. }\end{array}$ & $\begin{array}{l}\text { Form. } \\
\text { Code }\end{array}$ & $\begin{array}{l}\text { Disintegration Time } \\
\text { (Sec.) } \pm \text { SD }\end{array}$ & $\begin{array}{l}\text { Wetting Time } \\
\text { (Sec.) } \pm \text { SD }\end{array}$ & $\begin{array}{l}\text { Water } \\
\text { Absorption ratio }\end{array}$ & $\begin{array}{l}\text { Assay (\%) } \pm \\
\text { SD }\end{array}$ & $\begin{array}{l}\text { Fineness of } \\
\text { Dispersion }\end{array}$ \\
\hline 1. & F1 & $194 \pm 1.22$ & $84 \pm 0.33$ & $86.63 \pm 1.25$ & $91.86 \pm 1.66$ & Pass \\
\hline 2. & F2 & $183 \pm 1.06$ & $81 \pm 0.28$ & $78.85 \pm 1.32$ & $88.21 \pm 1.34$ & Pass \\
\hline 3. & F3 & $178 \pm 1.35$ & $80 \pm 0.62$ & $84.32 \pm 1.54$ & $93.54 \pm 1.25$ & Pass \\
\hline 4. & F4 & $154 \pm 1.21$ & $75 \pm 0.25$ & $85.32 \pm 1.01$ & $85.69 \pm 0.63$ & Pass \\
\hline 5. & F5 & $145 \pm 0.85$ & $76 \pm 0.36$ & $79.88 \pm 0.85$ & $88.79 \pm 1.20$ & Pass \\
\hline 6. & F6 & $142 \pm 0.93$ & $75 \pm 0.24$ & $91.23 \pm 1.21$ & $93.65 \pm 0.84$ & Pass \\
\hline 7. & F7 & $120 \pm 0.33$ & $64 \pm 0.11$ & $94.23 \pm 0.28$ & $99.59 \pm 0.25$ & Pass \\
\hline 8. & F8 & $135 \pm 0.84$ & $68 \pm 0.42$ & $88.21 \pm 1.32$ & $95.49 \pm 1.62$ & Pass \\
\hline 9. & F9 & $144 \pm 1.26$ & $69 \pm 0.47$ & $86.32 \pm 1.54$ & $98.56 \pm 1.11$ & Pass \\
\hline 10. & F10 & $148 \pm 1.54$ & $69 \pm 0.32$ & $87.25 \pm 1.28$ & $97.65 \pm 0.84$ & Pass \\
\hline
\end{tabular}

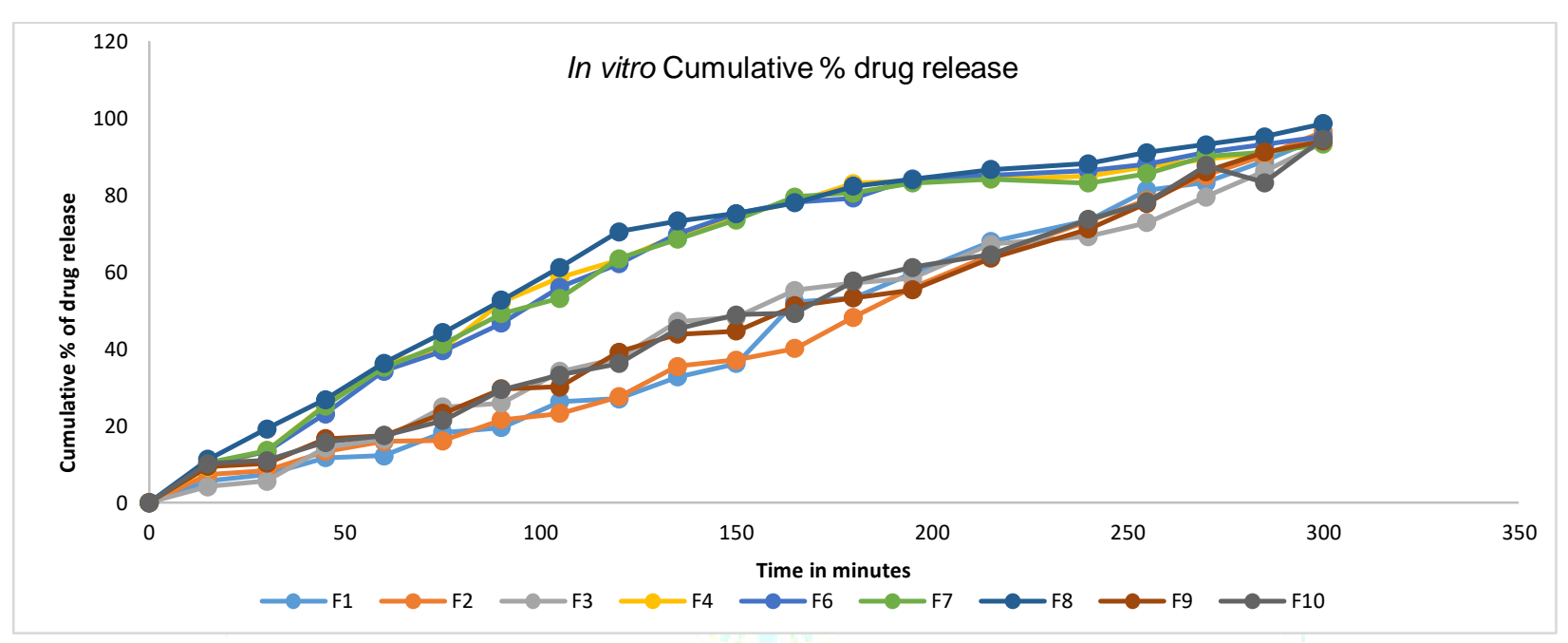

Figure 4: In vitro Cumulative \% drug release profile of ODTs

\section{DISCUSSION}

The ODTs of PMZ were successfully prepared with various quantity of super disintegrants (MCC, CCS and SSG) by wet granulation technique. The pre-compression characterization of mixed blends was done for the determination of mass-volume relationships as well as flow properties.

The present ODTs of PMZ, the taste-masking, was achieved within the 2 minutes that indicates the PMZ was not released from the tablet core or the released amount was below the human threshold level for fingering its bad taste. Therefore, it might be evidenced that the taste masking was successfully achieved by Okra mucilage. Aside from all the characteristic peaks of PMZ also appeared in the same wavenumber of the spectrum in the physical mixture and the coated formulation. From the comparative study, it was observed that these two spectra were almost the same. It indicated the absence of interaction between the drug and the excipients. The peak shape of DSC thermogram and the melting point is slightly changed from pure Okra mucilage due to entrapment of PMZ 17. The DSC thermograms of (Figure 3) of PMZ (curve S1), the physical blend of PMZ and all excipients (curve S13) has minor changes in the melting endotherm of the PMZ could be due to the mixing of drug with the impurities present in the excipients. The endothermic peak of individual excipient as well as a physical mixture of excipients with the drug clearly describes the integrity and compatibility of excipients with PMZ.

The powdered bland has an excellent flow property 30. Tablets have a superior mechanical strength indicating frriability below 1\%. In the dissolution study (Figure 8), it was observed that the drug release property was significantly increased with the increasing concentration of super disintegrant SSG ${ }^{29}$ due to the porous structure SSG is facilitating rapid water uptake into the tablets 31 .

\section{Selection of optimized formulation}

The optimized formulation was selected based on the characteristics of compressed tablets (general appearance, weight variation, thickness and diameter, hardness, friability, disintegration time, waiting time, water absorption ratio, In vitro dissolution study in PBS $\mathrm{pH}$ 6.8). Based on the abovementioned parameters, among all formulations, F7 was found to be the best formulation in all respects. The average weight of the tablets was found to be $375.02 \mathrm{mg}$, with a maximum deviation of \pm 0.63 . The average tablet thickness was $4.0 \pm 0.02 \mathrm{~mm}$. The hardness of the tablets was $4.7 \pm$ $0.11 \mathrm{~kg} . \mathrm{cm}^{-2}$ and disintegrated within 3 minutes, which assured the constant drug release from ODTs (shown in table 8 ). The average percentage loss of weight in the friability test was found to be $0.34 \%$ with a standard deviation of \pm 0.02 , which assured tablets have the adequate mechanical strength to resist abrasion, capping and chipping in packaging, handling and transportation. PMZ content was $99.59 \%$, with a standard deviation of \pm 0.25 . It suggested uniformity and minimum intra-batch variability in tablets.

\section{In vitro drug release kinetics of optimized formulation}

The In vitro drug release kinetic of F7 was determined by plotting cumulative percent drug released versus time (Figure 4). The correlation coefficient $\left(\mathrm{R}^{2}\right)$ of zero order, first order and Higuchi model were 0.996, 0.5704 and 0.9613 respectively (Table 9). The $\mathrm{R}^{2}$ value suggested that the PMZ released from the ODTs follows zero-order kinetics. The 
Korsemeyer- Peppas-model (Eq. 9) was used to understand the release mechanisms, where $\mathrm{n}$ is the diffusional exponent. The value of $n$ was estimated by plotting $\log \left(\mathrm{M}_{\mathrm{t}} / \mathrm{M}_{\infty}\right)$ of drug release from the tablets versus $\log t$. The value of $n$ was found to be 0.81 , which can be ascertained by the release of PMZ from ODTs. It follows the anomalous (Non- fickian) mechanism ( $\mathrm{n}$ value in between $0.45<\mathrm{n}<0.89$ ) 29 .

Table 9: Correlation coefficient $\left(\mathrm{R}^{2}\right)$ and diffusional exponent $(\mathrm{n})$ of optimum formulation batch.

\begin{tabular}{|c|c|c|c|c|c|c|c|c|}
\hline \multirow{2}{*}{ Formula Code } & \multicolumn{2}{|c|}{ Zero Order model } & \multicolumn{2}{|c|}{ First Order model } & \multicolumn{2}{|c|}{ Higuchi model } & \multicolumn{2}{|c|}{$\begin{array}{l}\text { Korsemeyer- } \\
\text { Peppas model }\end{array}$} \\
\hline & $\mathrm{K}_{0}$ & $\mathrm{R}^{2}$ & $\mathrm{~K}_{1}$ & $\mathrm{R}^{2}$ & $\mathrm{~K}_{\mathrm{H}}$ & $\mathrm{R}^{2}$ & $\mathrm{n}$ & $\mathrm{R}^{2}$ \\
\hline F7 & 0.497 & 0.996 & 1.0917 & 0.5704 & 9.4253 & 0.9613 & 0.81 & 0.9843 \\
\hline
\end{tabular}

\section{CONCLUSION}

The oral dispersible tablets of a bitter drug by using Okra mucilage as a taste-masking agent are beneficial as well as commercially applicable. Moreover, ODTs were rapidly dispersed in the buccal cavity and released the drug immediately. From the dissolution profile, it was observed that the drug release property was significantly increased with the increasing concentration of super disintegrant SSG. The formulation has followed an anomalous (Non- fickian) mechanism of drug release from ODTs.

\section{CONFLICT OF INTEREST}

The authors confirm that this article content has no conflict of interest.

\section{REFERENCES}

1. Gryczke A, Schminke S, Maniruzzaman M, Beck J, Douroumis D. Development and evaluation of orally disintegrating tablets (ODTs) containing Ibuprofen granules prepared by hot melt extrusion. Colloids Surfaces B Biointerfaces, 2011;86:275-84.

2. Que L, Wu W, Cheng X, Hu T. Evaluation of disintegrating time of rapidly disintegrating tablets by a paddle method. Pharm Dev Technol, 2006;11:295-301.

3. Tan Q, Zhang L, Liu G, He D, Yin H, Wang H, et al. Novel tastemasked orally disintegrating tablets for a highly soluble drug with an extremely bitter taste: Design rationale and evaluation. Drug Dev Ind Pharm, 2013;39:1364-71.

4. Suryadevara V, Lankapalli SR, Danda LH, Pendyala V, Katta V. Studies on jackfruit seed starch as a novel natural superdisintegrant for the design and evaluation of irbesartan fast dissolving tablets. Integr Med Res, 2017;6:280-91.

5. Habib W, Khankari R, Hontz J. Fast-dissolve drug delivery systems. Crit Rev Ther Drug Carrier Syst, 2000;17:61-72.

6. Schettler T, Paris S, Pellett M, Kidner S, Wilkinson D. Comparative pharmacokinetics of two fast-dissolving oral Ibuprofen formulations and a regular-release Ibuprofen tablet in healthy volunteers. Clin Drug Investig, 2001;21:73-8.

7. Sunada H, Bi Y. Preparation, evaluation and optimization of rapidly disintegrating tablets. Powder Technol, 2002;122:188-98.

8. Schiermeier S, Schmidt PC. Fast dispersible Ibuprofen tablets. Eur J Pharm Sci, 2002;15:295-305.

9. Sindhu RK, Puri V. Phytochemical, nutritional and pharmacological evidences for Abelmoschus esculentus (L.). J Phytopharm, 2016;5:238-41.

10. Mishra A, Clark JH, Pal S. Modification of Okra mucilage with acrylamide: Synthesis, characterization and swelling behavior. Carbohydr Polym, 2008;72:608-15.

11. Hoang Thi TH, Morel S, Ayouni F, Flament M-P. Development and evaluation of taste-masked drug for paediatric medicines Application to Acetaminophen. Int J Pharm, 2012;434:235-42.

12. Hesari Z, Shafiee A, Hooshfar S, Mobarra N, Mortazavi SA. Formulation and taste masking of ranitidine orally disintegrating tablet. Iran J Pharm Res, 2016;15:677-86.

13. Madgulkar AR, Bhalekar MR, Padalkar RR. Formulation design and optimization of novel taste masked mouth-dissolving tablets of Tramadol having adequate mechanical strength. AAPS PharmSciTech, 2009;10:574-81.

14. Cantisani C, Ricci S, Grieco T, Paolino G, Faina V, Silvestri E, et al. Topical Promethazine side effects: Our experience and review of the literature. Biomed Res Int, 2013;2013.

15. Malamed SF, Malamed SF. Pharmacology. In: Stanley F. Malamed, editor. Sedat. A Guid. to Patient Manag. $5^{\text {th }}$ ed., Los Angeles, California: Mosby; 2010, p. 316-54.

16. Sharma G, Garg G, Kulkarni GT. Taste masking of Promethazine hydrochloride using Eudragit E100 via solid dispersion technique to develop fast disintegrating tablets development of novel particulate drug delivery system for traditional Ayurvedic / Unani medicines. Der Pharm Lett, 2010;2:83-94.

17. Sharma HK, Lahkar S, Nath LK. Extraction, characterisation and compatibility study of polysaccharides from Dillenia indica and Abelmoschus esculentus with Metformin hydrochloride for development of drug delivery system. Int J PharmTech Res, 2013;5:275-83.

18. Ameena K, Dilip C, Saraswathi R, Krishnan PN, Sankar C, Simi SP. Isolation of the mucilages from Hibiscus rosasinensis linn. and Okra (Abelmoschus esculentus linn.) and studies of the binding effects of the mucilages. Asian Pac J Trop Med, 2010;3:539-43.

19. Farooq U, Malviya R, Kumar Sharma P. Extraction and characterization of $0 \mathrm{kra}$ mucilage as pharmaceutical excipient. Acad J Plant Sci, 2013;6:168-72.

20. Lee CS, Chong MF, Robinson J, Binner E. Optimisation of extraction and sludge dewatering efficiencies of bio-flocculants extracted from Abelmoschus esculentus (Okra). J Environ Manage, 2015;157:320-5

21. Das RJ, Bhuyan B, Sharma HK. Fixed dose oral dry syrup combination of Norfloxacin and Tinidazole using natural polysaccharides: Formulation and evaluation. Drug Deliv Lett, 2016;6:77-89.

22. Abu-Huwaij RT. Promising polymeric buccoadhesive bilayered tablets releasing valsartan: effect of gel strength. Jordan J Pharm Sci, 2018;11:2018-119.

23. Puttewar TY, Kshirsagar MD, Chandewar AV, Chikhale RV. Formulation and evaluation of orodispersible tablet of taste masked Doxylamine succinate using ion exchange resin. J King Saud Univ - Sci, 2010;22:229-40.

24. Sharma D, Kumar D, Singh M, Singh G, Rathore MS. Taste masking technologies: A novel approach for the improvement of organoleptic property of pharmaceutically active substance. Int Res J Pharm, 2012;3:108-16.

25. Xu J, Bovet LL, Zhao K. Taste masking microspheres for orally disintegrating tablets. Int J Pharm, 2008;359:63-9.

26. Nagar P, Singh K, Chauhan I, Verma M, Yasir M, Khan A, et al. Orally disintegrating tablets: Formulation, preparation techniques and evaluation. J Appl Pharm Sci, 2011;1:35-45.

27. Bhuyan B, Das RJ, Sharma HK. Fixed dose combination of targeted release paediatric dry syrup containing Ofloxacin and Ornidazole using natural polymers: Formulation and characterization. Egypt Pharm J, 2016;15:132.

28. Koland M, Sandeep V, Charyulu N. Fast dissolving sublingual films of Ondansetron hydrochloride: Effect of additives on In vitro drug release and mucosal permeation. J Young Pharm, 2010;2:216-22.

29. Das S, Murthy PN, Nath LK, Chowdhury P. Kinetic modeling on drug release from controlled drug delivery systems. Acta Pol Pharm Drug Res, 2010;67:217-23.

30. Mohan S. Compression physics of pharmaceutical powders: A review. Int J Pharm Sci Res, 2012;3:1580-92.

31. Pabari R, Ramtoola Z. Effect of a disintegration mechanism on wetting, water absorption, and disintegration time of orodispersible tablets. J Young Pharm, 2012;4:157-63. 